\title{
The scope for collective action in a large groundwater basin: an institutional analysis of aquifer governance in Western Australia
}

\author{
James H. Skurray a, b, * \\ ${ }^{\text {a }}$ Centre for Environmental Economics \& Policy, University of Western Australia \\ M089, 35 Stirling Highway, Crawley, WA 6009, Australia \\ ${ }^{\mathrm{b}}$ National Centre for Groundwater Research \& Training \\ an Australian Government initiative with headquarters in Adelaide, SA, Australia \\ * Corresponding author \\ E-mail address: jhs36@cornell.edu \\ $24^{\text {th }}$ November 2013 (Revised May 2014) \\ Working Paper 1313, School of Agricultural \& Resource Economics \\ www.are.uwa.edu.au
}

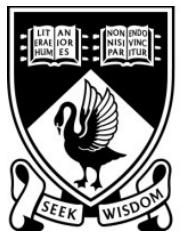

\section{THE UNIVERSITY OF WESTERN AUSTRALia \\ Achieve International Excellence}

Citation for this working paper version: Skurray, J.H., 2014. The scope for collective action in a large groundwater basin: an institutional analysis of aquifer governance in Western Australia. Working Paper 1313, School of Agricultural and Resource Economics, University of Western Australia. Available via http://purl.umn.edu/161075.

NOTICE: This is the author's version (preprint) of a work that was accepted for publication in Ecological Economics. Changes made to this work since it was submitted for publication, and changes resulting from the publishing process, are not reflected in this document. A definitive version was subsequently published in ECOLOGICAL ECONOMICS, VOL 114 (JUNE 2015), as:

Skurray, J.H., 2015. The scope for collective action in a large groundwater basin: an institutional analysis of aquifer governance in Western Australia. Ecological Economics, 114, 128-140.

The published journal article is available via the following link: http://dx.doi.org/10.1016/j.ecolecon.2014.12.015.

(c) Copyright remains with the authors of this document. 


\section{Abstract}

The Gnangara groundwater system in Western Australia occupies some 2,200km², supports multiple ecological systems and human uses, and is under unprecedented stress due to reduced rainfall and over-extraction. The basin is currently managed according to command and control principles by the state's Department of Water. This paper examines some of Ostrom's "situational variables" for the analysis of institutional choice - the selfprovision of institutional arrangements in common-pool resources situations - as they relate to the Gnangara case. The paper approaches the topic of collective action not as a niche concept which may be fitted only to certain specific cases, but as a basic and natural mode of human co-operation and interaction when faced with inter-dependent interests and in the absence of militating factors. We therefore conduct the analysis from the perspective of identifying elements of the current management approach - as well as of the shared norms, expectations, and attitudes of the appropriators - which could be altered to allow collective governance to develop, at least at some scale within the overall management regime. We use data from a set of water licence documents obtained from the Department of Water, among other data sources. A number of factors are identified as inhibiting the development of collective action at present. Current arrangements are topdown in nature, with all rules, monitoring, and enforcement supplied by the state-level management agency. Current norms and expectations among the appropriators appear to be competitive rather than co-operative, and discount rates appear to be high. In view of the size of the resource, and the large number and heterogeneity of appropriators, we conclude that the use of 'nested' organisational units - beginning at the smaller scale - will be a key component of efforts to develop the requisite social and institutional capital. Further, we conclude that there are several historical and other factors in this case whose net effect is to prejudice the unassisted development of collective action institutions by appropriator efforts alone, and that significant external support will be required from government agencies. This study highlights some important aspects of the regulatory apparatus in place, their likely effects upon the resource appropriators in terms of attitudes and behaviours, and the resulting impacts on the common-pool resource upon which wildlife, ecosystems, and the appropriators all depend.

\section{Keywords}

Institutions; governance; common-pool resources; commons; collective action; institutional analysis; 


\section{Introduction}

Successful management of common-pool resources (CPRs) is one of the most difficult and pressing problems facing natural resource management and environmental economics. Environmental problems at all scales can involve common-pool aspects. Examples include global-scale issues such as rising greenhouse gas levels, and damage to ocean fisheries, across their range of scales, by extraction in excess of flows to the detriment of stocks. Specific human activities also have impacts across scales. Pesticide pollution of water occurs at various scales depending on hydrological conditions, whereas 'drift' onto neighboring fields of toxins from the same source is a localised effect. ${ }^{1}$ California vehicle emissions standards are a local measure aimed at addressing a commons problem which also has global aspect. Groundwater basins are an important instance of common-pool resources, and there is widespread evidence of failure to manage these resources sustainably (e.g., Glennon, 2002; Esteban \& Albiac, 2011).

A reason for the difficulty is the fundamental tension - fostered and brought to the surface in many instances by the governance regime in place - between private rights in the flow and common interests in the viability and wellbeing of the stock. Pure public goods are both non-subtractable and non-excludable, the lighthouse being the oft-cited example. In such cases it is unnecessary to distinguish between a stock and flow. In common-pool resources, however, this distinction is important. CPRs are subtractable resources of sufficient size that exclusion of "potential beneficiaries" from their use is "costly but not impossible" (Ostrom, 1990, p. 30). The stock - a fishery for example - may be owned by a group of users, whereas the flow of benefits from use of the resource - in this case the catch in a given period - is appropriated by individual users. Thus there is a common interest in the viability of the stock, but private interests in the flow. Approaches which allow private rights in flows to dominate common interests in the stock (thus depreciating it) will be unsuccessful.

As in society more broadly, much thinking on the subject of CPR management has been dominated by neo-classical economic concepts, both in Australia and elsewhere (e.g., re Australia: GHD, 2011; Grafton, 2005; Bjornlund, 2003; Brooks \& Harris, 2008; Crase et al., 2000; Skurray et al., 2012; re the United States: Howe, 1997; Glennon,

1 Unlike $\mathrm{CO}_{2}$, airborne pesticides do not represent a uniformly mixed atmospheric pollutant; the size of the common pool in this case is defined by the local range over which the polluter can render an impact. 
2009; Howitt, 1994; Sunding, 2000; re Chile: Hearne \& Easter, 1997; and as described by Bauer, 2004). Such is the pervasiveness of this paradigm that, in some quarters, norms and orthodoxies have formed, favouring market-based approaches to resource management. This is despite the fact that these approaches may not be best suited to accommodating the tension between private and common interests.

Countering the tendency for market concepts to be applied to all areas of life, are strong arguments that there are subjects to which they ought not to be applied. As Ostrom stresses the dangers of applying models out of their range (1990), Sandel makes clear that markets have limits outside which it may be neither appropriate nor desirable to apply them; he recommends that we "rethink the reach of markets into spheres of life where they don't belong" (2009, at minute 9). Schumacher warned in 1973 against applying economics itself out of its range. That Sandel's cautions are necessary, even now, shows the extent to which Schumacher's earlier ones have yet to be heeded. As Sandel puts it: "[I]ooking back over three decades of market triumphalism, the most fateful change was [...] the expansion of markets, and of market values, into spheres of life traditionally governed by non-market norms" (2009, @ min 10). In this environment it has been easy for alternative governance approaches - even those borne out by extended histories of success - to be left with a smaller share of the discourse than they deserve.

Contributing to this problem, and reinforced by it, has been the misconceived dichotomy between markets and market-based instruments on the one hand, and command and control regimes on the other. ${ }^{2}$ This perceived dichotomy has tended to draw attention away from the fact that markets and command \& control are not the only two options. It has also been a distraction from the important insight that markets in fact exist within the institutional context established by legislation and regulation, meaning that the two are far from being opposites (Haddad, 1996; Blomquist, 1998; Norgaard, 2010).

Collective governance is characterised by institutional innovation and investment by resource users, thus - ideally - aligning the interests in flows with those in the stock's wellbeing. Since many environmental problems consist in the excess private

2 For example, while Harrington and Morgenstern acknowledge that most of their studied policies used "at least some elements of both approaches", their paper preserves and perpetuates the clear distinction (2004, p. 13). 
appropriation of resource units to the detriment of an associated stock, the prospect of aligning interests in the two is compelling. Collective governance arrangements operating (with at least some success) include, as examples:

- the management of traditional common lands in Japan (McKean, 1986);

- the Oukaimedene agdal (rangelands) in Morocco (Gilles et al., 1986);

- commonfield farming in Peru and Bolivia (Campbell and Godoy, 1986);

- Spanish irrigation institutions at Valencia, Alicante, and elsewhere (Ostrom, 1990);

- Filipino irrigation societies (Ostrom, 1990);

- Southern California groundwater basins (Ostrom, 1990; Blomquist, 1992);

- the fishery at Alanya, Turkey (Ostrom, 1990);

- the Eastern La Mancha aquifer in Spain (Esteban \& Albiac, 2012);

- $\quad$ pilot programs in New Zealand for 'audited self management' (Holley and Lawson, 2014).

Collective management is an alternative to - or may complement - both centralized and market-based management approaches to CPRs. Indeed, as noted by Blomquist, "while common-property arrangements are distinguishable from completely governmental/regulatory and completely private/market arrangements, they are not inherently incompatible with either, and often coexist and overlap with both" (1998, p. 4).

Despite its successes and history of academic attention, collective governance is not given due consideration as a potential management option; in many cases it appears simply to be absent from the 'menu' of approaches considered. In some CPR situations, this may be because neither the users nor the existing management agency has sufficient awareness of the potential of collective management approaches. A more substantive reason may be the large scale at which some environmental problems are experienced, and the insufficiency of the requisite social 
capital at the relevant scale (or a lack of jurisdictional congruence with resource boundaries). ${ }^{3}$

In approaching medium-to-large scale CPR problems, the question of the number of individual decision-makers looms large in terms of the potential tractability of collective governance arrangements (e.g., Olson, 1965). Though Ostrom analyzes several successful cases of large numbers of appropriators (up to 13,500) providing their own governance institutions, it may be too easy to use size - of a resource or the body of users - as a justification for dismissing this governance mode. It is true that, for CPRs with many users, impediments may exist across a wider range or on a larger scale. Familiar impediments may also be more severe - for example, the number of users with divergent interests and high discount rates may be larger, and absences of mutual trust and transparency of actions more costly to overcome. It is not clear, however, that these costs increase constantly with the number of users. It can be argued that conditions currently prohibitive to collective action - even in large-scale CPRs - are not necessarily natural or immutable ones.

In cases where there is no experience with collective governance, it may be necessary to emphasise that the presence of impediments does not equate to an ex ante demonstration of inapplicability. For example, the issues presented by the size of the Gnangara groundwater system (GGS), and by the non-hydrological origins of its internal administrative sub-divisions, do not constitute fundamental impediments but present challenges because of current human conceptual and behavioural norms. These are not static.

Indeed, existing impediments - both institutional and cultural - arise from the cumulative effects of past decisions. Path-dependency is important, both in terms of formal institutional choices, and informal, passive, or tacit societal decisions. ${ }^{4}$ Present-

3 Even in very large CPR situations it may be that elements of the collective governance approach can be useful where others exhibit weaknesses. In the context of $\mathrm{CO}_{2}$ emissions, for example, implementation of markets in emissions permits appears to derive as much justification from its promise as from past successes. Command and control on an international basis may face jurisdictional problems regarding enforcement.

4 An example is the current disproportionate standing and influence of the mining industry in Australia. The recent resource 'boom' - with its wide-ranging social and environmental impacts - has allowed a perception of the industry as nationally as well as economically important. This is possible only as a result of earlier decisions, such as not to limit financial dependence on finite resources, the nature of legislation governing limited liability companies, and their permissible interactions with the political and financial sectors of society. 
day impediments in any particular case reflect the effect of previous and existing institutions on the potential for collective governance. Blomquist and Schlager, for example, seek to account for the potential effects of "institutionally created heterogeneities on the abilities ... of resource users to voluntarily ... devise governing arrangements for coordinating their use of ... groundwater and surface water" (1997, p. 3). One of the deepest influences may arise from the tension between neo-classical economic instruments and social capital. Markets are not neutral. Their application and operation promotes particular attitudes toward the exchanged good. Sandel points out that "[o]ften, market incentives erode - or 'crowd out' - non-market incentives" (2009, @ min 15). In 1974, Arrow "stressed the importance of trust as the most efficient mechanism to govern transactions" (Ostrom, 2011 p. 62). Clearly, the choice to use market mechanisms influences subsequent norms and thus affects the policy options later considered, as well as their potential success.

This paper treats collective governance not as a special case, but as a fundamental mode of human interaction. We treat it as a broadly applicable governance mode with the potential to function in a range of cases, absent prohibitive contextual impediments. This may be equivalent to proposing a change of perspective: rather than considering a 'niche model' whose use is conceivable only under specific conditions, the task becomes one of examining and assessing the relevant contextual impediments. It is perhaps ironic that many impediments to human cooperation in the interests of realising shared benefits have an origin in (or at least are reinforced by) the imposition of command \& control or market-based management approaches.

\subsection{Aims}

It is clear that collective governance will not emerge spontaneously (i.e., without outside assistance) in the Gnangara case under current conditions. It already would have done so, were the prevailing institutional environment sufficiently facilitative. The question underlying this study is whether and how conditions could be altered such that collective governance could be facilitated.

Based on her study of CPR cases - in some of which collective action institutions have had long-term success in managing common-pool resources sustainably, and in some of which collective action has failed to produce positive results or has done so only 
tenuously - Ostrom (1990) presents a framework of factors that influence the ability of resource users to develop and sustain effective institutions for the management of common-pool resources on which they depend. This paper applies Ostrom's framework to a West Australian case study with the goal of assessing the potential for collective action as an alternative (or complementary) governance regime in the Gnangara case. The primary objective is the identification of the impediments to, and factors favouring, collective governance in this case, via an examination of the states of Ostrom's situational variables. A secondary objective is the assessment of whether collective governance is a realistic management option in this case, given the nature and tractability of the impediments identified.

Ostrom's groundwater cases are all in California, and are all cases in which collective management has been attempted. The institutional, legal, and cultural contexts examined in this paper differ considerably from those in California, and collective management has not been attempted in the case considered here. Data used in this analysis are extracted from water licences and related documents obtained from the Department of Water (part of the Government of Western Australia) under a Freedom of Information Act request.

In total, Ostrom describes 25 situational variables: nine "affecting judgement about the benefits of an institutional choice" (1990, p. 197); seven relating to "judgements about the costs of transforming status-quo rules" (p. 199); six regarding "monitoring and enforcement costs" (p. 203); and three relating to the internal norms and discount rates of appropriators. ${ }^{5}$ This paper examines a sub-set of ten of these, chosen on the basis of their particular relevance to the case study, and of the extent to which the available data inform them. The paper proceeds as follows: Section 2 provides an overview of the groundwater system, its uses, governance, and condition; Section 3

5 In this paper, the term 'discount rate' refers to the degree to which individuals discount future benefits and costs; that is, the degree to which they prefer immediate future benefits over distant future benefits. We use the term broadly, to include not only the concept of the opportunity cost of capital, but also the concept of time horizons. Ostrom uses the terms 'discount rate' and 'time horizons' to refer to similar ideas. For example, illustrating high discount rates, she observes that "[a]ppropriators who are uncertain whether or not there will be sufficient food to survive the year will discount future returns heavily when traded off against increasing the probability of survival during the current year" (Ostrom, 1990, p. 35). By contrast, low discount rates are enjoyed, for example, by "individuals [who] live side by side and farm the same plots year after year. They expect their children and their grandchildren to inherit their land. In other words, their discount rates are low" - and their time horizons are long (Ostrom, 1990, p. 88). 
presents the analysis of our selection of Ostrom's variables, based on the data obtained. Broader discussion and concluding remarks follow in Section 4.

\section{The Gnangara aquifer system - an overview}

The Gnangara system consists of several distinct water bearing layers, differing in their respective horizontal extents. The area managed by the Department of Water (the Department) as the 'Gnangara groundwater system' coincides with the horizontal extent of the superficial aquifer, and is the resource examined in this study. The system stretches approximately $90 \mathrm{~km}$ north along the West Australian coast from the mouth of the Swan River. It extends around $40 \mathrm{~km}$ inland (generally to the Darling Fault), giving it a land area of some $2200 \mathrm{~km}^{2}$. Beneath the superficial aquifer, in order of increasing depth, are the Mirrabooka aquifer ("semi-confined"), the Leederville aquifer ("partially-confined"), and the ("mostly-confined") Yarragadee aquifer (DoW, 2014a, p. 5). ${ }^{6}$ The superficial aquifer averages $45 \mathrm{~m}$ in thickness, with a maximum thickness of $75 \mathrm{~m}$ (DoW, 2009a).

\subsection{Uses}

Perth, a city of 1.7 million, extracts more than $50 \%$ of its municipal (public) water supply from the Gnangara groundwater system. Private (self-supplied) groundwater users in the study area include vegetable growers, fruit growers, plant nurseries, herb farms, turf farms, and vineyards, as well as domestic gardens. Self-supplied water is also extracted by local government entities for uses such as the irrigation of parks, and by industrial users. Over $90 \%$ of self-supplied extraction is from the superficial aquifer (DoW, 2014a, p. 10). Total licensed (plus estimated non-licensable) extraction from all aquifers in 2012-13 was $283.65 \mathrm{GL}$ (DoW, 2014a). From the superficial aquifer in the same water year, licensed private extractions were $110.56 \mathrm{GL}$, an estimated 30 GL was withdrawn from private garden bores (which do not require a licence), and $31.52 \mathrm{GL}$ was licensed for public water supply (DoW, 2014a). ${ }^{7}$ Based on these figures, over $80 \%$ of superficial aquifer extractions are for private supply. For the terms of this study therefore, the superficial aquifer is the CPR - and its users are the appropriators

6 While the Mirrabooka aquifer underlies only part of the study area, both the Leederville and Yarragadee aquifers extend under a much larger area than the superficial aquifer. Overlapping, they underlie a combined north-south distance of some $700 \mathrm{~km}$, roughly from Geraldton to Augusta (GSST, 2009).

7 It should be stressed that these licensed entitlement figures are not to be taken as accurate measures of actual water use, as described below. 
- of primary interest. We concentrate particularly on the private users, nominally including the users of domestic garden bores, although the unlicensed nature of these leaves them necessarily to one side of much of the specific discussion. ${ }^{8}$ Extraction from the three deeper, partially-confined aquifers, represents $39 \%$ of total extraction from the Gnangara system, and, in contrast to the superficial aquifer, is dominated by withdrawals for public supply; some $76 \%$ of licensed public water supply extraction is from these three aquifers DoW, 2014a). ${ }^{9}$

\subsection{Governance}

The state's Department of Water manages water licensing in Western Australia. The Department is established - and its activities are based - in command-and-control principles, and its organisational culture reflects this (see Skurray et al., 2013).

The Department's 2009 Allocation Plan for the GGS briefly mentions "existing local water resource management committees" noting that only one such body exists within the plan area (the Gingin Dandaragan Water Resource Management Committee), explaining the legislative basis for its existence, and pointing out that "all government boards and committees" were (then-currently) under review (DoW, 2009a, p. 7). The Gnangara Sustainability Strategy's note on this committee is similarly ominous in terms of the prospects for its ongoing viability: "[t]he Gingin Dandaragan [...] Committee has had its terms of reference extended for a year, to June 2009, during which time it will support the Department of Water in determining the most appropriate consultation and advisory mechanisms available to the department" (GSST, 2009, p. 113). In describing the need for a "coordinating body" to (inter alia) align and monitor the "implementation of management actions" the Gnangara Coordinating Committee stated the need for such a body to "include representatives from all agencies responsible for the required management actions" (GCC, 2009, p.

8 The issue of the garden bores is an important one, not least because of uncertainty in estimates of their impact. Syme notes the presence of "approximately 150,000 private bores in the city, representing at least $30 \%$ of detached houses" $(2011$, p. 362). Estimates of the number lying within the study area range from 72,500 (DoW, 2009a, p. 27) to 80,000 (GCC, 2009, p. 5). Greater uncertainty surrounds the volume of their combined extraction, with the Department now estimating usage at $30 \mathrm{GL}$ per year (DoW, 2014a), whereas earlier estimates were of 58 GL per year (DoW, 2009a, p. 27) and of "around 60" GL per year (GCC, 2009 , p. 25). Using the higher of these figures increases the proportions of water extracted both privately and from the superficial aquifer.

9 From these, respectively, public supply extractions in 2012-13 represented: Mirrabooka: $54 \%$ (of less than $5 \mathrm{GL}$ ); Leederville: $79 \%$ of approximately $54 \mathrm{GL}$; Yarragadee: more than $98 \%$ of around $52.5 \mathrm{GL}$ (DoW, 2014a, p. 10). The proportion of public supply extraction increases with aquifer depth. 
28); no mention was made of groundwater users. The Gnangara Sustainability Strategy produced a 140 page 'situation statement' in 2009. This document's section on governance observed "[g]overnance in relation to the Gnangara groundwater system involves the allocation of responsibilities across a range of state government agencies" (GSST, 2009, p. 104).

The system is administratively divided into eight 'groundwater areas', the boundaries of which are largely based on land-ownership boundaries rather than hydrogeological realities (Skurray et al., 2013). The superficial aquifer is further divided into 51 subareas.

\subsection{Condition}

Wetlands, lakes, and other groundwater dependent ecosystems are numerous in the study area, many of them seriously threatened by declining water levels. Eighteen sites across the GGS were non-compliant with one or more ministerial water level criteria in 2012-2013 (DoW, 2014a). Since the city's establishment, more than 75\% of the wetlands surrounding Perth have disappeared (Syme, 2011). Groundwater acidification due to declining water levels in the Gnangara area is placing the remaining groundwater dependent ecosystems at additional risk (Clohessy et al., 2013). ${ }^{10}$ Illustrating the disconnect between agency statements of intention on the one hand and the effective implementation of management measures - or the realisation of beneficial outcomes - on the other, the Department notes that its 2009 "allocation limits represented a target reduction in private abstraction of 10 to 13 per cent" (DoW, 2013, p. 12). The same document, however, records that the opposite outcome in fact eventuated; "total water licensed" increased significantly for each aquifer in the Gnangara system, and by $19 \%$ across the system overall, between the 2009-10 and 2010-11 water accounting years (DoW, 2013, p. 8). While we note that the stated target reduction was in private abstraction, and that $91 \%$ of the $45 \mathrm{GL}$ increase was in public supply allocations, private allocations also increased. Adding to

10 Clohessy et al. "recorded acidic groundwater ... flowing in a westerly direction towards Lake Mariginiup, Lake Joondalup and Lake Jandabup" (2013, p. 151). All three of these wetlands were identified on a 'risk map' in 2005 by the agency responsible, as being areas where groundwater-dependent ecosystems are especially vulnerable to damage from groundwater extraction (DoW, 2005, p. 13; see also Skurray \& Pannell, 2012). All three are also included in the eighteen non-compliant sites for 2012-2013. Despite documented failure to take proper account of the risk areas this map denotes, the Department refers to it in its 2013 'evaluation statement': "[i]n high-risk areas we use an environmental risk map to guide licence assessments and manage licence conditions so that pumping impacts are minimised where possible" DoW, 2013, p. 13. 
the direct pressure on surface ecosystems and human users, $18 \mathrm{GL}$ of the increased allocations were from the superficial aquifer (DoW, 2013, p. 9).

As we discuss below, users may be temporarily insulated from the conditions of the resource. Neither this insulation, however, nor current groundwater extraction levels are sustainable. The present management system has been ineffective in engendering appropriate use levels and the associated environmental protection (Nevill et al., 2010; DoW, 2014a; Skurray \& Pannell, 2012).

\section{Evaluating the situational variables}

To assess the likely net benefits of a change to the institutional arrangements governing their CPR, appropriators must consider prospective benefits and costs of such a change. As concrete information is usually unavailable for most of the relevant benefits or costs, the pertinent perceptions - or subjective conditions - are of great importance. In terms of the situational variables considered here, impediments can be seen as unfavourable states or levels of those variables. We begin with a discussion of variables affecting appropriator perceptions of the prospective benefits of a rules change. Secondly we consider variables affecting how prospective transformation costs would be perceived. We then turn to variables relating to monitoring and enforcement costs. Variables relating to internal norms and discount rates (or time horizons) follow. In some cases below, we establish the existence of 'second order impediments' - attributes of the current arrangements that act to impede the revelation of the state of the situational variables themselves. These are pertinent in terms of appropriator assessments of the net benefits of a rules change, but for the reason that they obscure information about the state of the appropriators' world rather than because they reveal it.

\subsection{Benefits}

A number of attributes of the current arrangements in the Gnangara case are identified as being likely to affect appropriator expectations of the benefits that would be derived from a rules change. 


\subsubsection{Temporal and spatial variability of resource units}

The size of a resource system, and the number of appropriators, increase the cost of obtaining accurate information on resource conditions and the value of future flows under any rules. Unpredictable flows of resource units have a similar effect. This can "be offset [...] if data on resource conditions, resource-unit quality, prices and appropriation levels are recorded regularly", which they are not in this case (Ostrom, 1990 p. 196).

Temporal and spatial variability in this case are real but masked. The 10-year fixed annual volumetric water entitlements (AVWEs) used in the Gnangara system mask the underlying temporal variation in the resource, limiting the availability of information regarding a variable which itself influences judgements about the benefits of rules change (a second order impediment). The annual volumetric entitlements may also actually exacerbate natural variability by ignoring it; insisting on last year's consumption this year may reduce the availability of next year's resource flows.

The presence of instruments such as the 'irrigation development assessment form' implies to users that temporal and spatial variability of resource units are low. AVWEs may contribute to this subjective underestimation of resource unit variability. Going further, this type of instrument impairs user appreciation for the concept of resource flows (in the sense of stock and flow), replacing it with a misconception of the 'flow' as any quantity a user can extract. The instrument design may arise from, but also reinforces, a fundamental conceptual and cultural disconnection, represented by the idea that Nature will provide whatever can be forcibly wrung from her.

Temporal variability also varies spatially. Temporal variability may be higher, for example, near a wetland. Far from taking this into account, current arrangements specify an unvarying location of extraction as well as a unvarying annual volumetric allowance. This combination further obscures underlying natural variability, distorting estimations of future flows under any rules.

\subsubsection{Unpredictable market prices}

Market prices are of course a key source of information regarding the value of future flows under any rules and thus in estimations of the benefits of any rules change. Were there a well-functioning market in the case examined here, prices would be a 
source of information on resource variability as well. There are several reasons why the prices paid on transfers and leases in this case, however, are as uninformative as they are. Market price is a function of scarcity and demand. Where permitted consumption is artificially decoupled from scarcity, prices cannot reflect this important information. The AVWE creates a false lack of the scarcity premium by not distinguishing between sustainable extraction and groundwater mining (i.e., consumption in excess of the rate of renewal, that depletes the stock and is therefore unsustainable by definition). The effect on prices is extended and compounded by the instrument's 10-year duration, and the natural variation of price with resource conditions is missing. ${ }^{11}$

Under the current Gnangara regime, the licensing system specifies an authorised use or purpose to which extracted water is to be put. This restricts an appropriator's set of water use options, thus distorting both the opportunity cost of sale and the willingness to pay of a buyer. While this may artificially increase the predictability of the prices we do have, it limits their informational content as indicators of the value of future flows under rules without the authorised activity restriction.

Not only do prices in this case have very little informational content, but they are also secret. The transfer application process makes prices publicly unavailable. Price secrecy, in terms of informational content, is equivalent to extreme price unpredictability. Price secrecy represents a barrier to obtaining information on the value of future flows under any rules - either current or proposed. Under rules which allowed prices to impound more information, their non-public nature would be a particularly costly feature.

\subsubsection{Other factors}

There are several further unintended consequences of the AVWE instrument. By disconnecting appropriation levels from sustainable availability, the annual volumetric entitlement removes the usefulness of appropriation levels as a source of shared knowledge about resource conditions - including knowledge shared by the regulator. Users' private knowledge of their own water table levels is not a substitute for shared knowledge of overall conditions.

11 Allocation of shares in a sustainable overall extraction volume, using monitoring well levels to determine availability, is an alternative approach; prices under that regime could properly reflect scarcity. 
The annual entitlements also affect perceptions of the value of future flows under rules which would require sustainability. By conferring a right to continued unsustainable extraction levels, the current volumetric entitlements would cause sustainable extraction volumes to appear much lower by comparison. The endowment effect, combined with high discount rates (as discussed below), increases the likelihood that sustainable withdrawals would actually be seen as worth less than the current groundwater mining volumes. ${ }^{12}$ So little actual information is available to users in this case regarding the value of future flows, that perceptions must be based on little hard evidence. By skewing these perceptions, current arrangements increase the costs to users (and to the regulator) of obtaining accurate information on resource conditions and the value of future flows. The AVWEs appear to discourage long-term stewardship attitudes, increasing the discounting of any future flows, and exacerbating the above effect.

Compounding the effect of these perceptions are the numerous examples of lax enforcement by the regulator in this case. There is a pervasive failure to collect even basic information from users (such as appropriation levels and prices paid on transfers, for example). It appears that this has created a mutually reinforcing set of norms. The regulator's organisational culture appears to include little expectation of gaining accurate and timely information from users. Users in turn, we suggest, have developed a norm of obfuscation, concealment, or simple omission, with the result that it is now needlessly costly for the Department to obtain information from them generally. ${ }^{13}$ The overall result is that neither the regulator nor the regulated knows overall current usage rates or their values, and can have little expectation of realistically estimating the value of future flows under either the present rules or any alternative.

\subsubsection{Subjective conditions}

As well as upon "the objective conditions of the CPR", perceptions of potential benefits from rules changes depend upon subjective conditions: the "type of information that

12 The subjective value of future flows depends on resource conditions under future rules - not only on the size of flows, but on their sustainability - and on the discount rate or time horizon perspective of the viewer (i.e., on the private NPV of all future flows).

13 The prevalence of blanks or unreported prices - and numerous other omissions - on transfer application forms, and the common non-submission of required meter records, are examples. 
the current institutional arrangements generate and make available to individuals" (Ostrom, 1990, p. 197-198).

The Department has several forms, reports, and standard letters (the 'incident investigation briefing sheet' and 'formal letter of warning', for example) which variously appear to substitute for enforcement, or which recommend it but are then internally ignored. An effect of this is to 'generate and make available' to users the information that there is an absence of a functioning regulator, or at least of a willing one. An unstated purpose of some of this paperwork appears to be to allow users to provide the regulator (or for the Department to provide itself) with opportunities to justify the avoidance of effective enforcement action. Partly as a result of this, individuals also learn that the condition of the CPR must be acceptable - or at least cannot be dire - otherwise serious regulatory enforcement would by now have been in evidence. The message conveyed to users, in the absence of enforcement of their own extraction limit, is that in all likelihood other users' limits are also going unenforced. Thus a 'race to the bottom' is encouraged. ${ }^{14}$

An important component of subjective conditions are impressions of regulatory intent. The 'compliance survey notice' advises users of an imminent compliance inspection by the Department. Messages conveyed to users via this instrument are at best confusing, at worst misleading given that the aquifer system is under unprecedented stress. Self-supply users must be aware of falling water-tables, and CPR condition information is available at least to those users situated adjacent to vanishing wetlands, for instance. Yet the compliance survey notice makes no mention of overuse or of resource conditions; instead it clearly reads as though the inspection is to ensure users' full entitlements are being used. The compliance inspection appears to be driven by a development mindset. Few users can be expected to develop or maintain a conservation mindset in the face of such a regulatory environment. The issuance of 10-year licences would naturally cause users to conclude not only that resource conditions must be acceptable, but that current consumption levels are to some degree legitimate in terms of sustainability.

14The 'notice of proposal to direct compliance' (discussed further in the following section) is a striking example of lax enforcement which, overall, transmits a misleading impression to users regarding resource conditions. 
Further illustrating the disconnection of regulatory instruments from CPR wellbeing, the standard 'formal letter of warning' regarding non-submission of meter readings makes no mention of resource conditions. Regulatory communiqués like these, barren of useful informational content, forego a prime opportunity to promote among users an understanding of the CPR's nature and condition. Even once meter results have been submitted and found to be "in excess of licence entitlement", the resulting formal letter of warning also makes no mention of CPR conditions (DoW, 2010-2011, licence 158577, incident investigation briefing sheet, p. 1). ${ }^{15}$

Current rules also affect subjective conditions in terms of relationships between users. The confidentiality of metering records, and the shared knowledge that they are private, not only limit awareness of overall appropriation levels. They also create a veil of secrecy between users, and a resulting isolation of the individual user from her fellow appropriators. While licensed allocation volumes are publicly available (with effort and knowledge) actual consumption certainly is not. Indeed, even the Department knows the actual water usage of only a small percentage of users (see Skurray et al., 2013). This has the effect of artificially separating appropriators from each other - rendering them mutually less visible in terms of resource use, and importantly reducing a sense of shared involvement. ${ }^{16}$

\subsection{Transformation costs}

Regarding a prospective rules change, Ostrom sees the crucial ex ante calculation as being the assessment of transformation costs relative to expected benefits. "If the expected costs of transforming the rules are higher than the net benefits to be gained, no further cost calculations will be made" (Ostrom, 1990, p. 198).

Of course a key question is whether users have the autonomy to effect a change of rules (Ostrom, 1990; Blomquist, 2010). Equally important is that they perceive themselves to have such autonomy. In the case examined here, autonomy to change the rules is limited. Of primary interest for this study, however, is the fact that many

15 This particular letter details the Department's "proposed decision" to "amend" the licence by adding a condition that the "quantity of water that may be taken ... is limited to" the licensed entitlement (DoW, 2010-2011, licence 158577, formal letter of warning, p. 1). This, obviously, represents no change at all.

16 Ostrom cites shared involvement in situations outside their CPR as facilitating normreinforcing "encounters" between appropriators (1990, p. 206). The institutionally created separation discussed here reduces the sense of sharing even the resource itself. 
of the instruments and mechanisms of the current situation tend to reduce subjective impressions of autonomy. Indeed, many attributes of the current rules conspire to vacate the concept - to preclude its consideration in the users' option set.

One consideration in terms of appropriator autonomy to change the rules is requirements imposed by external authorities. The absence of such requirements in this case is not neutral; it both reflects and perpetuates an absence of awareness of the option itself. Current arrangements include restrictive provisions as well as lax enforcement. These do not offset each other, but instead create particular effects both individually and in combination. The authorised activity specification, for example, is so restrictive that it may reduce perceptions of user autonomy in general.

Two broader points pertain to transformation costs in this case. The ad hoc and lax nature of enforcement tends to obviate the idea of changing the rules because the alternative of ignoring or circumventing the current rules to use more water now, is a low cost strategy. Combined with high discount rates and a lack of the resource stewardship impulse, this prejudices prospects for a rules change by collective action, regardless of any actual autonomy to make such a change. This effectively increases transformation costs. Similarly, absent any user awareness of the regulator's requirements for rules change, and given regulatory behaviour in this case, it can be suggested that users would expect such requirements to be onerous and nonsensical. This increases what might be called latent impressions of transformation costs. ${ }^{17}$

\subsubsection{Past strategies of appropriators}

Past appropriator behaviour has direct bearing on transformation costs.

"Confrontational strategies", for example, cause transformation costs to "rise sharply"; "appropriators who share norms that restrain opportunistic behavior can adopt rules that are less costly to operate..." (Ostrom, 1990 p. 200). The evidence examined in this study is of appropriator behaviour with respect to the regulator rather than one to each-other, yet it illustrates norms which would tend to prejudice the accrual of social capital between users.

17 It also highlights the need to consider initiating institutional change incrementally or to begin at smaller scales in such cases. 'Small steps' may work by showing that positive change at some scale is possible, reducing subjective impressions of future transformation costs. 
Repeated patterns in the monitoring and enforcement behaviour of the regulator suggest that it has conditioned appropriators to engage in opportunistic or strategic behaviour. It has generally not been necessary for them to resort to actually confrontational strategies; the Department appears to seek opportunities to avoid enforcement action. In one 'incident investigation briefing sheet' the incident was the extraction of three times the licensed allowance. Another case, of metered use in excess of licensed entitlement, resulted in the decision to issue a "letter of warning acknowledging [user's] participation in [the] metering project but advising that they are still required to stay within their allocation" (DoW, 2010-2011, licence 57024, incident investigation briefing sheet, p. 2). The regulator is allowing for the implausible: that the presence of a meter could be misinterpreted as a substitute for compliance with allocation volumes. ${ }^{18}$

The 'compliance survey notice' advises licensees that those found "not using all of their water entitlements may be asked to complete a staged development to demonstrate the need for the water" (DoW, 2010-2011, licence 47400, compliance survey notice, p. 1). One interpretation of this is as an invitation to strategic behaviour, that is, to use water whether needed or not, in order to preserve the licence to do so.

Opportunistic, non-compliant behaviour may be undertaken at minimal cost. During one compliance inspection, extraction was estimated at 71,500 KL per annum. The user, licensed to extract only 47,550 KL per annum, subsequently received a 'notice of proposal to direct compliance' advising that the regulator was "considering issuing a direction to you to comply with the conditions of [your licence]" (DoW, 2010-2011, licence 45534, notice of proposal to direct compliance, p. 1). ${ }^{19}$ The regulator explicitly gave the licensee "the opportunity to present any additional information [...] before it makes its final decision" on the question of whether or not even to require compliance (DoW, 2010-2011, licence 45534, notice of proposal to direct compliance, p. 1). Four and a half years later, the same user was issued a 'formal letter of warning' concluding that the user had (again) "abstracted groundwater in excess of that approved"; the

18 The letter of warning as actually issued in this case did not include this clause. It had since been determined that "[n]o prima facie case could be established for these incidents" because the "anniversary date of water usage [was] not clear on the licences"; the resulting letter of warning included a specification of the annual water year (DoW, 2010-2011, licence 57024 , incident investigation briefing sheet, p. 2).

19 It is notable that the original compliance inspection took place only six weeks prior to the expiry of a 10-year licence; this raises the question as to the duration of the overuse prior to discovery. 
letter noted that "the Department has elected to manage the above breach by way of issuing a formal letter of warning" (DoW, 2010-2011, licence 45534, formal letter of warning, p. 1). ${ }^{20}$ The regulator's malleability is clearly communicated to users, granting tacit permission for opportunistic behaviour. By highlighting every chance the user has to object or obfuscate, the regulator not only appears to invite opportunistic behaviour, but also increases transformation costs as an unintended result.

After making two purchases of additional entitlements totalling 39,000 KL (nearly doubling their original allocation) this user's licence was reissued in 2010 with a further 10-year duration, and a licensed allocation of 86,550 KL (DoW, 2014b). The user is located in the over-allocated Mariginiup management sub-area. Their property borders Lake Mariginiup, "a wetland of high conservation value [...] denominated a zone of high risk to GDEs from groundwater extraction" on the Department's 2005 risk map (Skurray \& Pannell, 2012, p. 882). No explanation is included in the documents obtained for this study of these permitted transfers - of significant additional extraction volumes - to a location adjacent to this sensitive ecosystem.

\subsection{Monitoring and enforcement costs}

In the appropriator calculation of the net benefits from institutional transformation, ex post costs such as the prospective costs of monitoring and enforcement (M\&E) of the new rules are relevant only if "the ex ante costs of transforming the rules are not too high" (Ostrom, 1990, p. 198).

\subsubsection{Exclusion technology}

The exclusion technology chosen can be thought of as a response to the nature and layout of a resource; both these factors inform monitoring and enforcement costs (Ostrom, 1990). Effective exclusion in a CPR such as this one is difficult. Inefficiencies of the present system may have led to appropriators forming judgements about monitoring and enforcement in general; they may have been 'taught' by existing

20 This letter again proposes the 'amendment' that extractions be limited to the licensed entitlement, and also that the licensee submit meter readings and monthly extraction volumes to the Department each July. The letter stresses the "proposed" nature of the decision, and states that, even after a "final decision" is made, "should you be aggrieved [...] you may then exercise your rights of review" (DoW, 2010-2011, licence 45534, formal letter of warning, p. 2). 
arrangements that $M \& E$ is ineffective and/or may perceive it as illegitimate. This increases perceived prospective $M \& E$ costs under changed arrangements.

Part of the exclusion technology in this case is the granting or refusal of the volumes applied for in the licence applications. Based on several instances in the source documents of under-use being treated as non-compliance, more water than needed has been applied for and granted in many cases. This perpetuates a strategy of overstating required use during application, which is then compounded by the use-itor-lose-it provision of entitlements once granted. Through this unfortunate interaction between application process and ongoing compliance measures, the exclusion technology promotes overuse, and distorts user perceptions of prospective monitoring and enforcement costs under altered arrangements.

The net effect can be seen in the disconnect between users' perceptions of their own wellbeing and the wellbeing of the CPR. One case of a licence application refusal is illustrative of the exclusion technology being abused by the users it should protect. A large plant nursery applied for additional water in the Carabooda sub-area, which "is $111 \%$ allocated, [and where] there have been eight recent refusals [...] due to the aquifer reaching its sustainable limit" (DoW, 2010-2011, licence 53262, statement of reasons, p. 1). Citing declining water levels over 20 years, the Department concluded that "[t]he application is non-compliant" and "that the grant of this licence may prejudice the current and future needs for water..." (DoW, 2010-2011, licence 53262, statement of reasons, p. 2). Despite this, the applicant "indicated that he will follow the process to its finality in the hope of getting the additional water", i.e., by seeking State Administrative Tribunal review of the Department's decision (DoW, 2010-2011, licence 53262, permit refusal summary, p. 2). The lack of user support for the exclusion technology is further highlighted by the Department's concern that, should this licence be granted, other landowners could use "this application as a precedent in seeking further allocations" in an already over-allocated sub-area (DoW, 2010-2011, licence 53262, WLSU summary sheet - proposed refusal, p. 2).

\subsubsection{Marketing arrangement}

Certain marketing arrangements may provide a 'dividend' with respect to $M \& E$ costs versus others. The opacity of current marketing arrangements - the lack of price 
transparency, of brokers, etc - increases perceived prospective monitoring costs under changed rules. ${ }^{21}$

The current marketing arrangements do not help to reduce $M \& E$ costs - they do not provide an easy avenue for disclosure of prices or appropriation levels, as would a fish market, for example. The current arrangements generally have such high monitoring and enforcement costs - or are so ineffective at these activities - that the effectiveness of the market is impaired. There is a partial circularity here. A range of other factors also impinge upon the market's effectiveness (lack of binding overall extraction limits, lack of metering, price secrecy, the eligibility requirement on buyers). It remains true, however, that $M \& E$ costs are high in the Gnangara case, reducing the effectiveness of the market, which in turn increases M\&E costs (or at least foregoes their reduction), reducing the perceived net benefits of any changed rules.

\subsubsection{Shared norms relating to legitimacy of rules}

Ostrom's situational variable regarding "legitimacy of rules in use" refers to "legitimacy bestowed by external authorities on the results of institutional choices" (Ostrom, 1990 p. 203). In the Gnangara case we have no collectively generated 'rules in use' upon which the Department may or may not bestow legitimacy. For the current discussion, we turn to Ostrom's point that "shared norms related to the legitimacy of the rules ... will reduce the costs of monitoring..." (Ostrom, 1990, p. 204).

We suggest that via both instrument design and ineffectual implementation the Department undermines the perceived legitimacy of its own rules. By its very name, the notice of proposal to direct compliance advertises the tentativeness of the regulatory intent. The incident investigation briefing sheets and incident reports reveal aspects of the regulator's internal behaviours which can hardly fail to be manifested in their external ones. The conclusion is drawn that the existence of a shared norm among users relating to regulatory ineffectiveness (if not incompetence) is highly likely. Further, the compliance inspections are sufficiently ad hoc,

21 The good transacted in this case is the right to appropriate, rather than resource units themselves. The right is to the extraction of a fixed volume, however, rather than to a percentage share. This means that for the purposes of the current discussion, the marketing arrangement can be discussed in terms that are relevant to a delivered good, even though the good transacted differs qualitatively. 
perfunctory, and inconsequential that they must affect user impressions of how the regulator perceives the legitimacy of its own rules. ${ }^{22}$

A concrete example of the regulator's internal norms being transmitted to resource appropriators concerns the legitimacy of the so-called "metering project" and the "metering team". Rather than as central to the Department's mission, these were kept separate, marginal, and seem to be questioned even within the Department. ${ }^{23}$ The recalcitrance of the users in submitting their 'meter water use cards' (and the prevalence of warning letters on this subject) reflect a norm of ignoring the regulator for as long as possible, then meting out the minimal information. This is a further example of mutual reinforcement of a two-ended norm - in this case a norm that users and regulator are only going through the motions, together.

\subsection{Norms and discount rates}

Finally we consider the internal norms and discount rates (or time horizons) which determine how "individuals weight their own assessments of benefits and costs" (Ostrom, 1990, p. 205).

\subsubsection{Outside opportunities}

A direct influence on appropriator discount rates with respect to their CPR use is the presence of an alternative. This takes on a similar role to the 'best alternative to negotiated agreement' in negotiations theory (e.g., Perritt, 1986). By being "involved in activities that take them away from their CPR and into an economy in which other opportunities exist" (Ostrom, 1990, p. 206) CPR users can develop concepts about outside opportunities that exist elsewhere, potentially reducing their long-term reliance on the CPR, and increasing their weighting of present versus future benefits.

In the Gnangara case, horticulturists in the Wanneroo area have been concerned about “issues of land security (i.e., effects of urban sprawl) and groundwater availability ... threatening the longer-term viability" of their industry since at least 2005; "some

22 There is no indication that these reports are made available to users. Users are not necessarily present at inspections. Overall, the 'water survey' and 'compliance inspection' sheets give an impression of the relationship with the regulator as one of absence punctuated by sporadic, uninformative, and potentially confusing intrusions.

23 2009-10 is referred to as "the last year of the government funded metering program" (DoW, 2013, p. 12). 
horticulturalists fear[ed] that the industry eventually would be squeezed out due to encroaching urbanization" (DoE, 2005, p. 15). Discount rates regarding the CPR are raised by such expectations and concerns, in two ways. First, CPR stewardship attitudes (effectively valuations of the future wellbeing of the stock) are affected by the perceived exogenous impairment to long-term viability. Moreover, the encroaching suburbs present the alternative of selling land and ceasing operations: "[a]s a result of increasing land prices and constraints on operating practices many producers are selling their properties and relocating or taking the opportunity to sell and retire or move into other economic sectors" (SM / ECS, 2008 p. 7). The underlying problem of unsustainable urban sprawl is not addressed, but is treated as a given, as illustrated in the statement "[a] replacement for land that will be lost to domestic and industrial uses is urgently required" (SM / ECS, 2008 p. I). ${ }^{24}$ Instead, "it has been proposed that a dedicated horticulture precinct could relieve these land use pressures at Wanneroo and provide greater future land use certainty" for horticulturists (SM / ECS, 2008, p. 7). Of course, the proposed new location would use water from the same aquifer system, and thus it could be argued that the prospect of relocation should not cause appropriator discount rates to increase with respect to their current CPR use. The distance between the current and proposed locations, however, is such that (without additional information communicated by the regulator about the underlying nature of the resource) they could well be perceived as drawing from separate CPRs.

\subsubsection{Inculcation of myopia}

Ostrom points out that "shared norms can affect discount rates as much as can information about other opportunities" (Ostrom, 1990, p. 206). A social context in which "disregard for the future" is not "censured" facilitates increased private discounting; Greater Perth is certainly a place in which "no opprobrium is attached to seeking short-term gain in preference to long-term benefit" (Ostrom, 1990, p. 207). Aspects of Perth's cultural attitude to 'environmental values' can partly be illustrated by remarks by a senior Department of Water official, made during interviews for this study. With regard to the condition of the numerous wetlands in the study area, it was stated that "a lot of the wetlands ... have lost a lot of the conservation value ... either through urban encroachment ... or by fertiliser application ... . So a lot of the conservation values that first existed in that area may no longer be applicable today" (DoW, 2009b). The preference given to further suburban expansion at the expense of

24 This is not to imply that the remit of the Department of Water includes urban planning; the point is made to illustrate broader cultural and social norms and attitudes. 
numerous irreplaceable wetland habitats (some internationally recognised) illustrates the social context in which the Gnangara appropriators find themselves.

Underlying part of the greater Perth metropolitan area south of the Swan River is the Jandakot groundwater system. Like the Gnangara, this consists of a superficial aquifer overlying parts of the Leederville and Yarragadee aquifers. The Jandakot system underlies an area large parts of which are now urbanised, but which also includes two wetlands included in the Ramsar List of Wetlands of International Importance. Both these (Forrestdale and Thomsons lakes) have suffered water levels non-compliant with ministerial water level criteria for the past three water accounting years (DoW, 2014a). A further two wetlands dependent on water from the Jandakot system - both also suffering non-compliant water levels for the past three years - are Bibra and North lakes. While a plan to build a major highway extension between and partly through these two wetlands was recently "taken ... off the Government's agenda for the next four years" $(A B C, 2013)$, its existence is a poignantly neat illustration of prevailing attitudes. $^{25}$

Adding to the effects already described, the Gnangara appropriators are subject to a particularly influential exogenous factor affecting discount rates. Ostrom observes that "if a CPR can be destroyed by the actions of others, no matter what local appropriators do, even those who have constrained their harvesting from a CPR for many years will begin to heavily discount future returns, as contrasted with present returns" (1990, p. 35). While the majority of groundwater used for public supply is drawn from deeper aquifer layers, its effects are felt in the superficial aquifer (GCC, 2009; Pigois et al., 2010; DoW, 2014a). Its effects are also felt in terms of users' discount rates. And although only $\sim 22 \%$ of licensed superficial aquifer extractions are for public water supply, it represents not only a significant portion of total use, but is licensed to a single monolithic user who is responsible for a much larger bloc of use. Water Corporation extractions represented $\sim 45 \%$ of the estimated total volume withdrawn from all aquifer levels in 2012-13 (DoW, 2014a, p. 10). Depending on their perceptions of the interconnectivity between the aquifers, and of the spatial distribution of Water Corporation extractions, users may have the impression that they are ultimately in competition for water with much of metropolitan Perth. The

25 SBW (2014), for example, provides further information, including images relating to the proposal. 
unquantified extractions and unlicensed nature of the domestic garden bores, again depending on users' perceptions thereof, could contribute to this impression.

There is an intimate relationship between regulatory instruments and appropriator attitudes. Given the influences of the social context and the public water supply issue in this case, the potential positive role of regulatory instruments is of increased importance. Rather than fostering a resource stewardship norm, however, many of the instruments in this case appear to encourage or inculcate myopia. As Blomquist notes, for example, "'[u]se it or lose it' systems, in which usage rights that are not exercised in the current period cannot be claimed or used later, create incentives that are inconsistent with resource preservation and protection" (2010, p. 629). As well as affecting the condition of the CPR directly, non-enforcement also affects user discount rates. It is clear to users that little effective attention is given by the regulator to the actual condition of the CPR. This knowledge, combined with private information about falling water levels (even if not couched in terms of the unsustainability of current overall extraction levels) creates a sense of urgency, promoting the 'race to the bottom'. Restraint by individual users in the midst of these conditions may appear pointless. If anything, letters of warning from the regulator could exacerbate this, acting similarly to the 'use-it-or-lose-it' provision: if read as a signal of possible future enforcement of entitlement volumes, current consumption could be substituted for anticipated reductions in future consumption.

\section{Discussion and concluding remarks}

\subsection{Discussion}

As Ostrom notes, "one must view [institutional-choice processes] as historical processes whereby current decisions are built on past decisions" (1990, p. 202). Existing impediments arise from the cumulative effects of past decisions. In this case, both the formal institutional choices and the tacit decisions of the appropriators and regulator alike, continue to sustain the current institutional edifice. A number of factors are identified as inhibiting the development of collective governance at present. 
Neither the 10-year AVWE itself, nor its institutional context, provides any inculcation of stewardship in the resource user. Current arrangements impede the revelation of accurate CPR condition information, while simultaneously damaging present and future resource conditions and distorting users' time horizons. The known presence of expensive consultants' reports, bought by larger / wealthier players to justify extraction levels, could also work to raise the discount rates of less wealthy players.

As well as being hampered by the nature of some of its own instruments, there is ample evidence of the regulator's failure to make appropriate use of others. Invitations to justify the avoidance of enforcement action appear to be characteristic of the regulatory culture in this case. Elements of the current arrangements which users perceive as highly restrictive and arbitrary, as well as weakly enforced, tend to reduce their perceived legitimacy.

The current exclusion technology is not only costly in itself, but also generates high monitoring and enforcement costs without commensurate effectiveness. Examples of documents illustrating this include the 'incident report', the 'compliance survey notice', the 'incident investigation briefing sheet', and the 'notice of proposal to direct compliance'.

“Once [institutional-choice] decisions of a particular type have been made, future options will be strongly affected" (Ostrom, 1990, p. 202). Path dependence also applies to the strategic decisions taken by both regulator and appropriator. Most of our examples are of regulatory behaviour influencing appropriator perceptions. An inverse example is the appropriator decision to appeal to the State Administrative Tribunal against a licence application refusal. While not an institutional-choice decision, this is a decision to engage with the full extent of the current arrangements. Future options are affected. User conduct - in this case adversarial conduct against an already lax regulator - provides an 'upward' transfer (from the user to the regulator) of behavioural information that, repeated over time, would affect the organisational norms of the agency. In the aggregate, user actions can be seen as impounding tacit institutional decisions.

An important improvement, and a simple antidote to some of the above (particularly the paucity of shared knowledge of actual CPR conditions) would be to make the water 
table level mutually observable. A means of achieving this would be by a network of monitoring wells, situated such that groups of private users would share a particular monitoring well. Each user would manage their own water table level in private, but the monitoring well level, made public, would provide shared knowledge of local resource conditions. Publication of the water levels across the system would facilitate shared knowledge of overall resource conditions. And, importantly, this method would also provide the unavoidable recognition amongst users (and the regulator) of having that shared knowledge.

A broader implication of this study is that the current regulatory environment exhibits more, and more urgent, shortcomings than its counteraction of collective governance. The governance regime in place fails to manage the underlying tension between private rights in the flow and common interests in the viability and wellbeing of the stock. Indeed, many aspects of the current regime appear to bring this tension to the surface. It is both excessively rigid in structure and too flexible in implementation; it creates alienation between the regulator and the user; and it fails to protect groundwater-dependent ecosystems in the process. It appears, in the light of these failures, that the Gnangara case warrants a re-evaluation of the current regulatory system.

\subsection{Concluding remarks}

The pervasiveness of command and control and neo-classical economic approaches has in many cases crowded out due consideration of viable and potentially more effective alternatives, even those with long histories of demonstrated effectiveness. In many CPR situations, this may mean that neither the users nor the existing management agency has sufficient awareness of the potential of collective management approaches. This study identifies elements of the current management approach which could be altered to allow collective governance to develop, at least at some scale within the overall management regime. The current management approach affects and informs the shared norms, expectations, and attitudes of the appropriators, and of the regulator's own internal culture. We examine the links between these elements, and their likely influence on the current potential for collective governance in this case. 
We do not make a precipitous recommendation to implement, but this study's examination of the impediments to collective governance suggests that, while a long way from trivial, they are not immutable. There is the potential for conditions to be changed to favour a collective governance outcome, but its development would require effort and the revision of long-held underlying assumptions. Also necessary would be a shared appreciation of both the urgency of management reform and the potential of collective governance to contribute to the meeting of social and resource management goals.

The persistence of a development mindset on the part of the regulator is counterproductive in the presence of over-consumption and associated environmental damage. While the Department recognises that there is a CPR condition problem, nonenforcement of various of its own provisions contributes to resource degradation, as well as compounding user mis-perceptions of the CPR's nature and condition. The long-term nature of the current licences has numerous subjective as well as objective effects. Accurate information regarding CPR conditions is supplanted by the misconception that conditions must be acceptable. Several aspects of the current arrangements foster an impression of competition for water, rather than cooperation in its responsible use. This may contribute to a sense of urgency, promoting the substitution of current consumption for future consumption. Current arrangements, and the regulator's organisational culture, increase the costs of obtaining accurate information on resource conditions and the value of future flows. Actual usage rates and their value are unknown.

The current organisational culture within the regulating body in this case is counter to the development of user-supplied institutional change. For such change to develop, it would be necessary for the regulating body not only to understand and accept the potential for collective governance to contribute to the management of this resource, but actually to assist in its development (including, as Blomquist notes, "assist[ing] resource users [...] at the resource level in establishing some of the organizations and practices that will facilitate management" (2010, p. 624)). The current regulatory organisational priority is the administration of the management regime currently adopted. Collective action is not, of course, an option for management by the regulator, but it is an option for the management of the resource, and it remains currently unconsidered. Changing the organisational knowledge and awareness of collective governance may require and/or precipitate a corresponding change in the 
organisational culture. The development of trust, social capital, and governance institutions at smaller scales is important; these can then facilitate the development of new institutions at larger scales, and/or can be nested within existing ones as described in some of Ostrom's cases (1990).

It may be necessary for an outside agent (perhaps a group of users) to clarify to the Department (and possibly to the responsible minister) how collective action could align with its management goals. Going further, the management goals of the current regulator are clearly not the only ones relevant, and may have evolved to include such things as self-protection, political expediency, maintenance of the status quo; it may be necessary for an outside entity to demonstrate the potential of institutional selfsupply by the CPR users to provide sustainable and environmentally responsible management where the current regime does not.

This study provides an examination of an environmentally and economically important groundwater system from a novel perspective. Previous studies concerning the Gnangara system have not sufficiently examined the regulatory environment in terms of its impact on the resource and its users. The interactions between user and regulator, and the mutually reinforcing culture that these produce, are important in determining the impacts of flow appropriation on the stock of the resource, and are a key component of any resource management system. These interactions have not been examined in this way previously with respect to the Gnangara system; to the author's knowledge this is the first such study in this case. Scope for further research is extensive (although should not be used as a reason to delay management action which is urgently needed). A survey of groundwater users in the area could confirm, amend, or extend the conclusions suggested here. An examination of the extent and causes of regulatory capture in the case-study could lead to important ameliorative changes.

\section{Acknowledgements}

The author is grateful to the following people and organisations, among others. Professors Edella Schlager and Geoff Syme, and Dr Ellen Hanak very kindly reviewed an earlier version. Professor David Pannell provided research infrastructure, guidance, and the freedom to pursue this avenue of inquiry. Dr Jeff Connor provided advice and 
encouragement. Professor Michael Lockwood suggested the tension between neoclassical economic instruments and social capital. Professor Alex Gardner was instrumental in negotiations with the Department of Water, and provided subsequent advice. A discussion with Joseph Guillaume suggested the sharing of monitoring wells by groups of private users, recommended here. Ann Pelaez Londoño offered support and encouragement. The research was funded by an Australian Postgraduate Award. Funding was also provided by the National Centre for Groundwater Research \& Training, which is an Australian Government initiative supported by the Australian Research Council and the National Water Commission.

\section{References}

ABC (Australian Broadcasting Corporation), 2013. Premier Colin Barnett says contentious Roe Highway extension will not be built in this term of government. Available via http://www.abc.net.au/news/2013-10-16/roe-highwaydelay/5026812, accessed April 22, 2014.

Bauer, C., 2004. Results of Chilean water markets: empirical research since 1990. Water Resources Research 40. doi:10.1029/2003WR002838.

Bjornlund, H., 2003. Efficient water market mechanisms to cope with water scarcity. Water Resources Development 19 (4), 553-567.

Blomquist, W., 1992. Dividing the Waters: Governing Groundwater in Southern California. ICS Press, San Francisco, California.

Blomquist, W., 1998. Common property's role in water resource management. 2nd International Conference on Property Rights, Economics and Environment. July 6-8, Universite d'Aix-Marseille.

Blomquist, W., Dinar, A., Kemper, K.E., 2010. A framework for institutional analysis of decentralization reforms in natural resource management. Society \& Natural Resources 23 (7), 620-635.

Blomquist, W., Schlager, E., 1997. Property rights, political power, and the management of ground and surface water. Prepared for presentation at the Western Political Science Association annual meeting. March 13-15, Tucson, Arizona.

Brooks, R., Harris, E., 2008. Efficiency gains from water markets: empirical analysis of Watermove in Australia. Agricultural Water Management 95, 391-399. 
Campbell, B., Godoy, R.A., 1986. Commonfield agriculture: the Andes and medieval England compared. In: National Research Council (Ed.), Chapter 17 in Proceedings of the Conference on Common Property Resource Management. April 21-26, 1985. National Academy Press, Washington, D.C. 323-358.

Clohessy, S., Appleyard, S., Vogwill, R., 2013. Groundwater acidification near the water table of the Superficial aquifer, Gnangara Mound, Swan Coastal Plain, Western Australia. Applied Geochemistry 36, 140-152.

Crase, L., O'Reilly, L., Dollery, B., 2000. Water markets as a vehicle for water reform: the case of New South Wales. The Australian Journal of Agricultural and Resource Economics 44, 299-321.

DoE (Department of Environment), 2005. Managing a sustainable future for the Gnangara groundwater resources: analysis of stakeholder issues and perspectives. Water Resources Division, Department of Environment, Government of Western Australia, Perth.

DoW (Department of Water), 2005. Managing abstraction in areas of declining water levels affecting groundwater dependent ecosystems on the Gnangara Mound. Allocation note. Department of Water, Government of Western Australia, Perth.

DoW (Department of Water), 2009a. Gnangara groundwater areas allocation plan. Water resource allocation and planning series. Department of Water, Government of Western Australia, Perth.

DoW (Department of Water), 2009b. Department of Water senior staff, personal communication, Nov, 2009.

DoW (Department of Water), 2010-2011. Gnangara groundwater areas water licensing records. Unpublished. Provided pursuant to a request submitted in March 2010 under the Freedom of Information Act 1992, S.12. Department of Water, Government of Western Australia, Perth.

DoW (Department of Water), 2013. Gnangara groundwater areas allocation plan: evaluation statement 2009-2011. Department of Water, Government of Western Australia, Perth.

DoW (Department of Water), 2014a. Environmental management of groundwater from the Gnangara and Jandakot mounds: annual compliance report to the Office of the Environmental Protection Authority July 2012 to June 2013. Department of Water, Government of Western Australia, Perth. 
DoW (Department of Water), 2014b. The water register. Department of Water, Government of Western Australia, Perth. Available via http://www.water.wa.gov.au/ags/WaterRegister/, accessed May 8, 2014.

Esteban, E., Albiac, J., 2011. Groundwater and ecosystems damages: questioning the Gisser-Sánchez effect. Ecological Economics 70, 2062-2069.

Esteban, E., Albiac, J., 2012. The problem of sustainable groundwater management: the case of La Mancha aquifers, Spain. Hydrogeology Journal 20 (5), 851-863.

GCC (Gnangara Coordinating Committee), 2009. Gnangara sustainability strategy draft for public comment. Department of Water, Government of Western Australia, Perth.

GHD et al., 2011. A framework for managing and developing groundwater trading. Waterlines report, National Water Commission, Australian Government, Canberra.

Gilles, J.L., Hammoudi, A., Mahdi, M., 1986. Oukaimedene, Morocco: a high mountain agdal. In: National Research Council (Ed.), Chapter 15 in Proceedings of the Conference on Common Property Resource Management. April 21-26, 1985. National Academy Press, Washington, D.C. 281-304.

Glennon, R., 2002. Water Follies - Groundwater Pumping and the Fate of America's Fresh Waters. Island Press, Washington DC.

Glennon, R., 2009. Unquenchable: America's Water Crisis and What To Do About It. Island Press, Washington, DC.

Grafton, Q., 2005. Evaluation of round one of the market based instrument pilot program. Submitted to the National MBI Working Group, 17 August 2005.

GSST (Gnangara Sustainability Strategy Taskforce), 2009. Gnangara sustainability strategy situation statement. Department of Water, Government of Western Australia, Perth.

Haddad, B.M., 1996. Evaluating the Market Niche: Why Long-Term Rural-to-Urban InterRegional Markets for Water Have Not Formed in California. PhD dissertation. University of California, Berkeley.

Harrington, W., Morgenstern, R.D., 2004. Economic incentives versus command and control: what's the best approach for solving environmental problems? Resources Fall/Winter, 13-17. 
Hearne, R., Easter, K., 1997. The economic and financial gains from water markets in Chile. Agricultural Economics 15, 187-199.

Holley, C., Lawson, A., 2014 (in press). Implementing environmental law and collaborative governance. In: Martin, P., Kennedy, A. (Eds.), Meeting the Implementation Challenge of Legal Governance of Natural Resources. Edward Elgar.

Howe, C., 1997. Increasing efficiency in water markets: examples from the western United States. In: Anderson, T., Hill, P. (Eds.), Pages 79-99 in Water Marketing, the Next Generation. Rowman \& Littlefield, Lanham, MD.

Howitt, R., 1994. Empirical analysis of water market institutions: the 1991 California water market. Resource and Energy Economics 16, 357-371.

McKean, M.A., 1986. Management of traditional common lands (iriaichi) in Japan. In: National Research Council (Ed.), Chapter 24 in Proceedings of the Conference on Common Property Resource Management. April 21-26, 1985. National Academy Press, Washington, D.C. 533-592.

Nevill et al. 2010. Groundwater-dependent ecosystems and the dangers of groundwater overdraft: a review and an Australian perspective. Pacific Conservation Biology 16 (3), 187-208.

Norgaard, R.B., 2010. Ecosystem services: from eye-opening metaphor to complexity blinder. Ecological Economics 69, 1219-1227.

Olson, M., 1965. The Logic of Collective Action: Public Goods and the Theory of Groups. Harvard University Press.

Ostrom, E., 1990. Governing the Commons: the Evolution of Institutions for Collective Action. Cambridge University Press, New York.

Ostrom, E., 2011. Reflections on "Some unsettled problems of irrigation". American Economic Review 101, 49-63.

Perritt, H.H., 1986. Negotiated rulemaking in practice. Journal of Policy Analysis and Management 5 (3), 482-495.

Pigois, J-P., Johnson, S., Martin, M., 2010. A window to Perth's confined aquifers on the north Gnangara Mound. Groundwater 2010. November 1-4, Canberra.

Sandel, M., 2009. Markets and morals. Lecture 1 in A New Citizenship. The 2009 BBC Reith Lectures. Available at www.bbc.co.uk/programmes/b00kt7sh. 
SBW (Save Beeliar Wetlands), 2014. The Beeliar Wetlands. Available via http://www.savebeeliarwetlands.com/wetlands, accessed May 8, 2014.

Schumacher, E.F., 1973. Small is Beautiful: a Study of Economics as if People Mattered. Blond \& Briggs, London.

Skurray, J.H., Pandit, R., Pannell, D.J., 2013. Institutional impediments to groundwater trading: the case of the Gnangara groundwater system of Western Australia. Journal of Environmental Planning and Management 56 (7), 1046-1072. http://dx.doi.org/10.1080/09640568.2012.716368.

Skurray, J.H., Pannell, D.J., 2012. Potential approaches to the management of thirdparty impacts from groundwater transfers. Hydrogeology Journal 20 (5), 879891. http://dx.doi.org/10.1007/s10040-012-0868-9.

Skurray, J.H., Roberts, E.J., Pannell, D.J., 2012. Hydrological challenges to groundwater trading: lessons from south-west Western Australia. Journal of Hydrology 412413, 256-268.

SM / ECS (Science Matters / Economics Consulting Services), 2008. The feasibility of a new horticulture precinct on the Gnangara mound. Report prepared for the Department of Agriculture and Food, November 2008.

Sunding, D., 2000. The price of water: market-based strategies are needed to cope with scarcity. California Agriculture 54 (2), 56-63.

Syme, G.J., Nancarrow, B.E., 2011. Overcoming water scarcity in Perth, Western Australia. In: Grafton, R.Q., Hussey, K. (Eds.), Chapter 16 in Water Resources Planning and Management. Cambridge University Press, Cambridge. 